\author{
10IKC-346
}

\title{
DIAMONDS FROM THE EASTERN DHARWAR CRATON, INDIA: THEIR PHYSICAL AND INFRARED CHARACTERISTICS
}

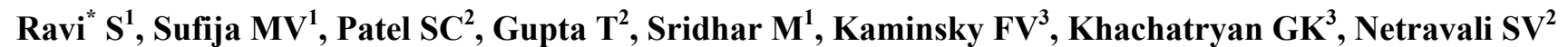 \\ ${ }^{1}$ Geological Survey of India, Bandlaguda Complex, Hyderabad 500068, India \\ ${ }^{2}$ Department of Earth Sciences, Indian Institute of Technology, Powai, Mumbai 400076, India \\ ${ }^{3}$ KM Diamond Exploration Ltd., 815 Evelyn Drive, West Vancouver, British Columbia V7T 1J1, Canada \\ Email: iyers_ravi@rediffmail.com
}

\section{INTRODUCTION}

Occurrences of kimberlites, lamproites and old workings of diamond in India can be broadly grouped into three diamond provinces, namely Southern Indian Diamond Province (SIDP), Central Indian Diamond Province (CIDP) and Eastern Indian Diamond Province (EIDP) (Fig. 1.). The SIDP is marked by both primary and secondary source rocks of diamond. The former includes Mesoproterozoic kimberlites spread over different kimberlite fields, while the latter includes Neoproterozoic conglomerate of the Banganapalle Quartzite formation, and the famed Quaternary gravel of the Krishna and Penner rivers. Many of the world famous diamonds such as the Koh-i-noor (186 ct), Great Mogul (787 ct), Pitt or regent (410 ct), Orloff (189 ct) and Hope (45 ct) were recovered from the Krishna gravel in the historic past. The link between the primary and secondary source rocks of diamonds in the SIDP remains unconstrained. A comparative study of infrared characteristics of diamonds from both the source rocks could provide important clues to the provenance of diamonds in the secondary source rocks.

Infrared characteristics of diamonds are a function of the concentration and form of substitutional nitrogen in the diamond lattice and are used to classify diamonds into spectral types: Ia (IaA and IaB), Ib, IIa and IIb. For southern Indian diamonds, the only available infrared study is by Wiens et al. (1990) who analysed a total of 8 diamonds including 4 from 3 kimberlite bodies of the Wajrakarur Kimberlite Field (WKF) (Fig. 2) and another 4 diamonds from the Krishna gravels. The diamonds were supplied to them by the Geological Survey of India (GSI). The reported diamond types include IaA, IaB, IaAB and IIa. In the present study 74 diamonds, mostly from the WKF and others from the Banganapalle conglomerate and Krishna gravel have been studied for their physical characteristics. Out of these stones, 51 have been characterized on the basis of infrared study for their nitrogen aggregation state.

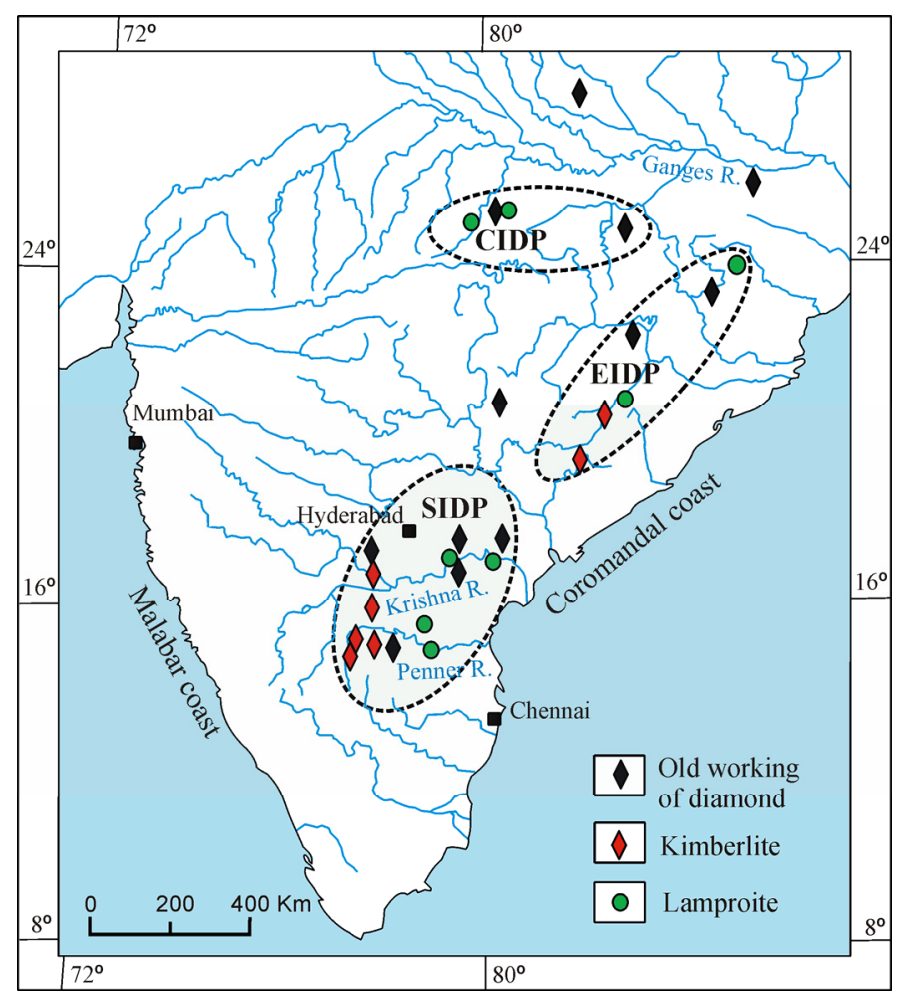

Fig.1. Map of peninsular India showing major river systems, diamond provinces, and old workings for diamond. EIDP = Eastern Indian Diamond Province; CIDP = Central Indian Diamond Province (CIDP); SIDP = Southern Indian Diamond Province.

\section{SOUTHERN INDIAN DIAMOND SOURCE ROCKS}

The SIDP is confined to the Eastern Dharwar Craton (EDC), which is an Archaean gneiss-granite-greenstone terrane with a major Proterozoic intra-cratonic sedimentary basin, called the Cuddapah basin (Inset of Fig. 2). The WKF occurs west of this basin and is the largest diamondiferous kimberlite field $(\sim 80 \mathrm{~km} \times 70 \mathrm{~km})$ in the Indian peninsula. So far a total of 45 kimberlite bodies are known from the WKF,

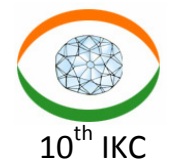




\section{$10^{\text {th }}$ International Kimberlite Conference-2012}

31 of which are distributed in four clusters: WajrakarurLattavaram (14 intrusions, P1-P14), Chigicherla (5 intrusions, CC1-CC5), Kalyandurg (6 intrusions, KL1-KL6), and Timmasamudram (6 intrusions, TK1-TK6). Most of these kimberlites were discovered by the GSI in the last three decades. The rest 14 intrusions of the WKF (WK1-WK14) have been discovered by M/s Rio Tinto Exploration but their locations are undeclared. The WKF kimberlites are usually small (surface area $<5$ ha) except for a few large bodies.

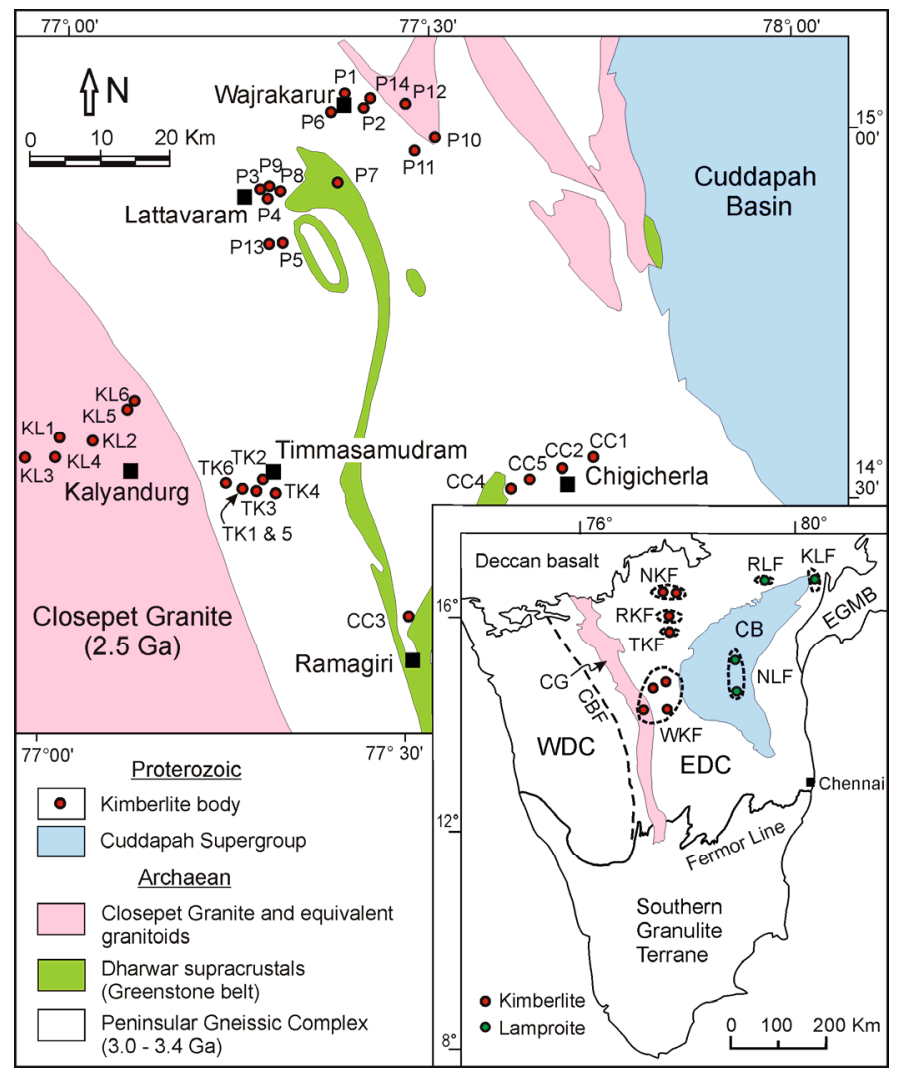

Fig.2. Generalised geological map of Wajrakarur Kimberlite Field (WKF). Inset shows sketch map of southern India with location of kimberlite and lamproite fields in the Eastern Dharwar Craton (EDC). $\mathrm{CB}=$ Cuddapah Basin; $\mathrm{CBF}=$ Chitradurga Boundary Fault; $\mathrm{CG}=$ Chitradurga Granite; KLF = Krishna Lamproite Field; NKF = Narayanpet Kimberlite Field; NLF $=$ Nallamalai Lamproite Field; RLF $=$ Ramadugu Lamproite Field; TKF $=$ Tungabhadra Kimberlite Field; WDC $=$ Western Dharwar Craton.

The Cuddapah basin is crescent shaped, easterly concave and is infilled by a $>10 \mathrm{~km}$ thick succession of clastic and chemical sediments belonging to the Cuddapah Supergroup (Palaeoproterozoic to early Mesoproterozoic) and Kurnool Group (Neoproterozoic). The latter occupies the Kurnool and Palnad sub-basins in the western and northern parts, respectively of the Cuddapah basin. The basal unit of the Kurnool Group is the Banganapalle Quartzite (maximum $50 \mathrm{~m}$ thick), which mainly comprises quartz arenite with local lenses (up to $3 \mathrm{~m}$ thick) of conglomerate (Fig. 3). This conglomerate in both the Kurnool and Palnad sub-basins was a well known secondary source of diamonds in the $17^{\text {th }}$ century and old workings can still be seen in different parts of the region. Old workings can also be seen within pebbly sandstones of the Mesoproterozoic Cumbum formation of the Cuddapah Supergroup that occur in the Kolluru area in the northeastern part of the Cuddapah basin (Fig. 4).

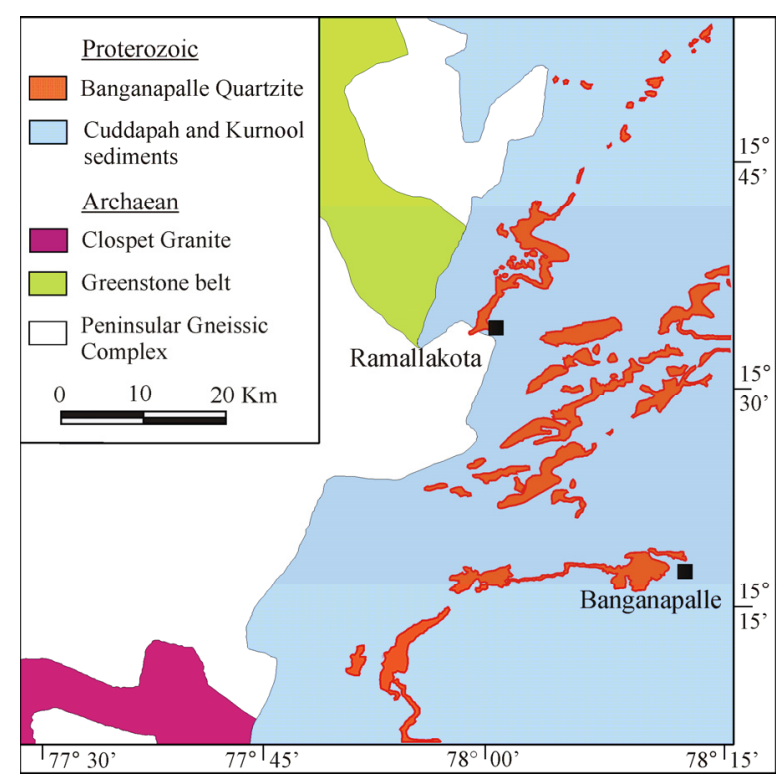

Fig.3. Generalised geological map of showing outcrops of Banganapalle Quartzite.

Quaternary gravel along the banks of the Krishna river for over $300 \mathrm{~km}$ distance is known as the host for ancient diamond workings. Diamond mining was most concentrated over a stretch of $\sim 60 \mathrm{~km}$ between Kolluru in the west to Paritala in the east (Fig. 4). The gravels occur in river terraces in the region upstream of Ustapalle. The region downstream of Ustapalle is a vast flood plain and the gravels in palaeochannels are now buried under thick alluvial cover. The gravels consist of well rounded pebbles, cobbles and boulders of quartzite, vein quartz, sandstone, jasper and agate. Besides, several old workings are recorded in Quaternary gravel along the banks of the Penner river.

\section{SOUTHERN INDIAN DIAMONDS}

The GSI processed large quantities of bulk samples from southern Indian kimberlites, gravels and conglomerates for their diamond incidence. For kimberlites, pit sampling was done up to a depth of $6 \mathrm{~m}$, except for the P1 and P6 kimberlites where sampling was done via underground

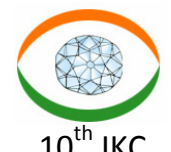




\section{$10^{\text {th }}$ International Kimberlite Conference-2012}

excavations. The materials processed for some of the pipes are: P1 (13,780 t), P2 (2,400 t), P7 (2,736 t), P10 (1,434 t), TK4 (228 t) and CC4 (88 t). Majority of the WKF kimberlites are poorly diamondiferous $(<2 \mathrm{cpht})$. The surface dimension and diamond incidence for some of the small but richly diamondiferous pipes are: TK4 (0.08 ha; $65 \mathrm{cpht})$, P7 (1.8 ha; $7.9 \mathrm{cpht})$ and CC4 (1.3 ha; $3.6 \mathrm{cpht})$, while those for some of the large but poorly diamondieferous pipes are: P1 (19 ha; $0.56 \mathrm{cpht}), \mathrm{P} 2$ (15 ha; $1.56 \mathrm{cpht}$ ) and P10 (63 ha; $1.0 \mathrm{cpht})$. The WKF diamonds are mostly of gem quality and the largest one recovered so far is from the P7 pipe $(16.30 \mathrm{ct})$. Microdiamonds have been reported from the Rio Tinto discoveries of kimberlites.

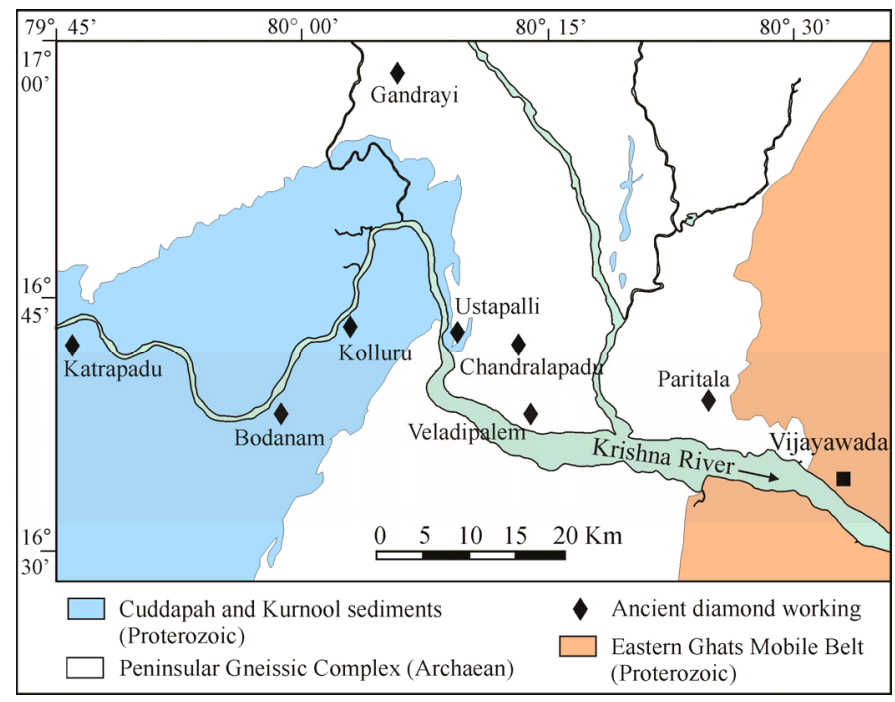

Fig.4. Generalised geological map around Krishna river showing ancient diamond workings. The area falls on the northeastern tip of the Cuddapah basin.

Although extensive old workings of diamond are seen in the Banganapalle conglomerate, exploration carried out by the GSI in different blocks covering this formation has not indicated high diamond incidence. The diamond grade is generally low (average $3 \mathrm{cpht}$ or less) and erratic, though high grades (up to $35 \mathrm{cpht}$ ) are locally recorded. The diamonds are mostly of gem quality with $<0.5 \mathrm{ct}$ weight, the largest one being $6.15 \mathrm{ct}$. The estimated resource of diamond in the conglomerate is $55,600 \mathrm{ct}$ in a total material of $\sim 5.2$ million tones.

Diamond incidence in the Krishna gravel is also quite erratic with spot values varying widely from 0.07 to 19.46 cpht. Most of the diamonds are of gem quality with an average weight of $\sim 0.83 \mathrm{ct}$. Nearly $40 \%$ of the diamonds are above 0.5 ct. The diamond resource estimated from different blocks covering the expanse of gravels is $99,390 \mathrm{ct}$ in a material of 19.46 million tones.

\section{Physical Characteristics}

Crystal forms and surface features of 74 macrodiamonds have been studied using optical microscope and Scanning Electron Microscope. The majority of the diamonds is from the WKF kimberlites (59), the rest coming from the Krishna gravels (10) and Banganapalle conglomerate (5). Most of the diamonds $(60 \%)$ are colourless, while the remainder of the population comprises brown, pink, yellow and green diamonds (Fig. 5). The two common diamond morphologies are dodecahedron (36\%) and octahedron (33\%), while a large fraction $(27 \%)$ shows irregular morphology. Only $4 \%$ of the sample suite can be considered main forms hexoctahedron and trisoctahedron. Diamonds from different kimberlite clusters of the WKF show broadly similar morphologies.

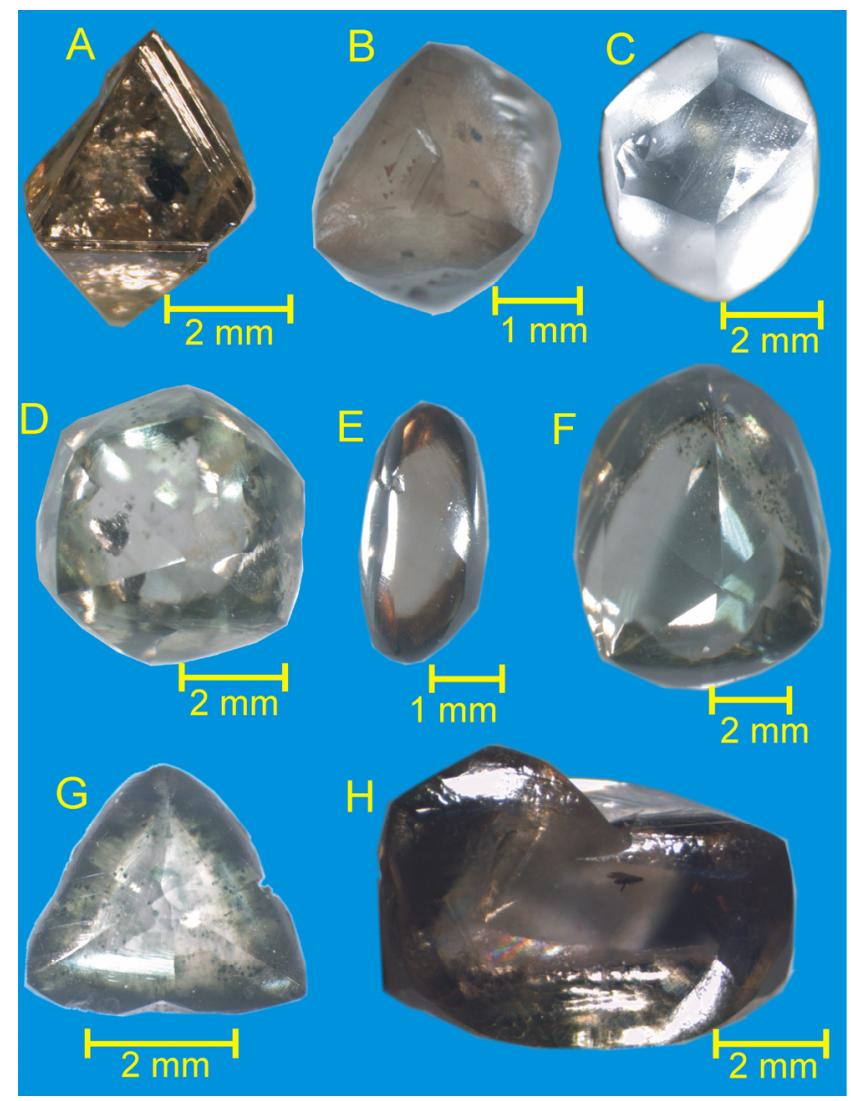

Fig.5. Representative crystal forms of southern Indian diamonds. (A) Octahedron; (B) Resorbed octahedron; (C) Dodecahedron; (D) Hexoctahedron; (E) Deltoid dodecahedron; (F) Trisoctahedron; (G) Macle; $(\mathrm{H})$ Geniculate twinned octahedra. Stones A, E and $\mathrm{G}$ are from kimberlites; stones B and C from conglomerates; and stones D, $\mathrm{F}$ and $\mathrm{H}$ from gravels.

A few diamond crystals show evidence of disequilibrium growth such as incomplete development of octahedral faces (Fig. 6C). Deformation laminations are observed in a small

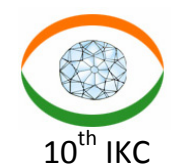




\section{$10^{\text {th }}$ International Kimberlite Conference-2012}

population of diamonds, especially in brown and pink diamonds (Fig. 6D). Such laminations are a manifestation of glide planes in diamonds and indicate that the diamonds were plastically deformed in the mantle (Mokievsky, 1962).

The southern Indian diamonds exhibit various degrees of resorption. Initial stage of resorption is expressed by etch pits of trigonal (Fig. 6A), tetragonal and pentagonal (Fig. 6B) geometry, and etch channels or ruts. Both positively- and negatively oriented trigonal etch pits are observed. Further resorption has resulted in rounded of edges and apices (Fig. 5B). Diamonds from the TK4 kimberlite of the Timmasamudram cluster show the least degree of resorption among all WKF diamonds.
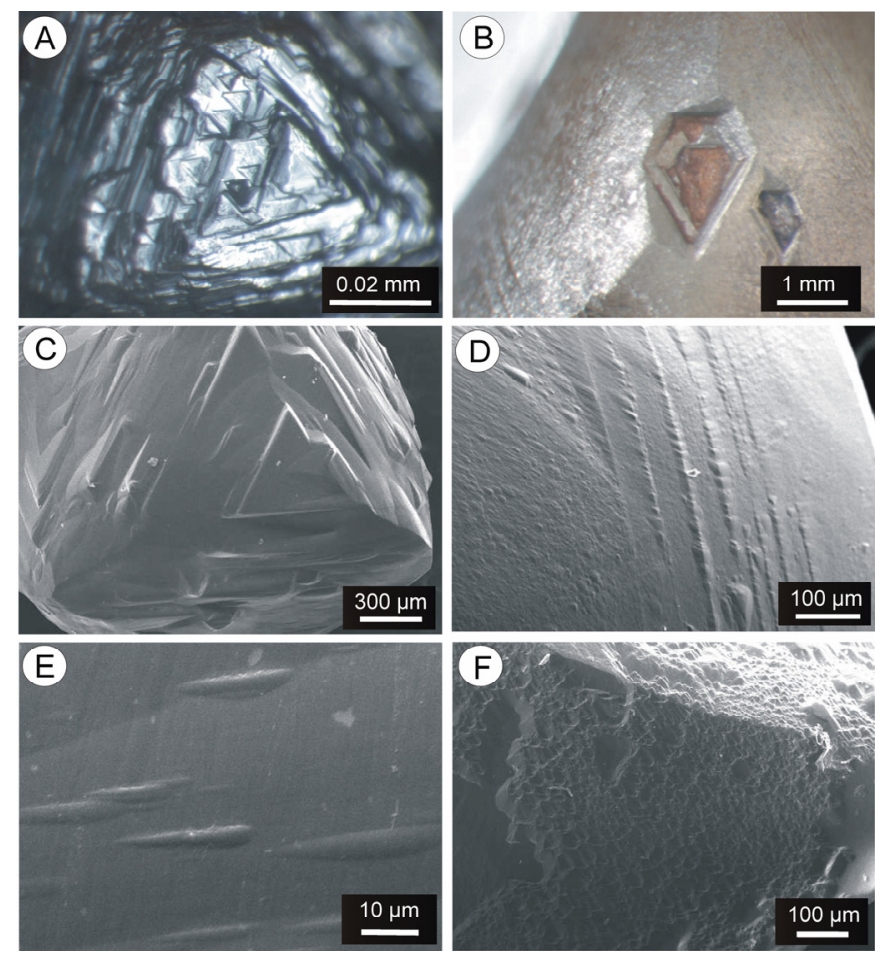

Fig.6. Optical photographs (A-B) and SEM images (C-F) showing surface features of southern Indian diamonds. (A) Trigonal etch pits; (B) pentagonal etch pit filled with secondary material; (C) incomplete octahedral growth; (D) lamination lines; (E) elongated hillocks; (F) frosting. Stones A and C are from kimberlites; stones B, D, E and F are from conglomerates.

Diamonds from conglomerates and gravels exhibit a variety of surface features such as shield-shaped laminae, serrate laminae, terraces, elongate hillocks (Fig. 6E), pyramidal hillocks, corrosion sculpture, and frosting (Fig. 6F). The gravel diamonds commonly display radiation damage (green and brown spots), and physical evidences of transportation such as percussion marks and network patterns. These features are absent in the conglomerate diamonds which indicates their relatively short-distance transportation.

Extended Abstract

\section{Infrared Characteristics}

Fourier-transform infrared spectroscopy (FTIR) was performed on 51 diamonds including 31 from P1, P3, P4, P6, P7, P8, P9, P10, TK4, CC1, CC2 and CC5 kimberlites of the WKF, 11 from Banganapalle conglomerates, and 4 from Krishna gravels. Absorption spectra were obtained using a Brucker Vertex 80 Infrared spectrometer (fitted with Hyperion 3000 microscope) at the Indian Institute of Technology, Bombay. Each diamond was represented by 1-4 spectra. In total 87 spectra were recorded by averaging the signals of 100 scans for each spectrum. The spectral resolution was 4-8 $\mathrm{cm}^{-1}$. Concentrations of $\mathrm{N}_{\mathrm{A}}$ and $\mathrm{N}_{\mathrm{B}}$ nitrogen impurities were determined from the absorption coefficients measured for corresponding bands in IR spectra using the following equations:

$$
\mathrm{N}_{\mathrm{A}}=\mathrm{K}_{\mathrm{A}} * \mu_{1282(\mathrm{~A})} ; \mathrm{N}_{\mathrm{B}}=\mathrm{K}_{\mathrm{B}} * \mu_{1282(\mathrm{~B})}=\mathrm{K}_{\mathrm{B}}{ }^{*} * \mu_{1175(\mathrm{~B})} ;
$$

where, $\mathrm{N}_{\mathrm{A}}$ and $\mathrm{N}_{\mathrm{B}}$ are the concentrations of $\mathrm{A}$ - and B-centres in at.ppm, respectively; $\mathrm{K}_{\mathrm{A}}=16.5 \pm 1$ at.ppm (Boyd et al., 1994), $\mathrm{K}_{\mathrm{B}}=79.4 \pm 8$ at.ppm (Boyd et al., 1995) and $\mathrm{K}_{\mathrm{B}}{ }^{\prime}=$ 26.6 at.ppm (Khachatryan, 2003) are the coefficients for Aand B-centres, respectively; $\mu_{1282}$ and $\mu_{1175}$ are the values of absorption peaks at frequencies of $1282 \mathrm{~cm}^{-1}$ and $1175 \mathrm{~cm}^{-1}$, respectively. The values of $\mu_{1282(\mathrm{~A})}$ and $\mu_{1282(\mathrm{~B})}$ for A- and Bcentres in each analysis were calculated according to Bokii et al. (1986). Results of these calculations are in full agreement with the results calculated following the method by Mendelssohn and Milledge (1995).

The major feature of the southern Indian diamonds is a great variety of stones in respect of their nitrogen concentrations, nitrogen aggregation, and even in their types (Fig. 7). The total nitrogen content, in the studied diamonds, varies from 0 (some diamonds from $\mathrm{P} 1, \mathrm{CC} 1$ and $\mathrm{CC} 2$ kimberlites) to 600-700 and even 1718 at.ppm (P7 kimberlite). The diamonds belong to four major groups: Group 1 (low-nitrogen), Group 2a and Group 2b (medium-nitrogen), and Group 3 (high-nitrogen). The proportion of aggregated nitrogen $\left[\% \mathrm{~N}_{\mathrm{B}}=100 \mathrm{~N}_{\mathrm{B}} /\left(\mathrm{N}_{\mathrm{A}}+\mathrm{N}_{\mathrm{B}}\right)\right]$ in the diamonds also varies greatly, in the range of $0-85 \%$, i.e. from Group 1 (highly-aggregated nitrogen) through Group 2 (intermediate) to Group 3 (low-aggregated nitrogen) (Kaminsky and Khachatryan, 2001). The proportion of non-aggregated nitrogen A center varies from $15 \%$ to $100 \%$. As a result, diamonds belong to different types of physical classification: $\mathrm{IaAB}$, IaA and IIa. The proportion of low-nitrogen stones (type IIa and near IIa) is above the average (over $25 \%$ ). Assuming the same duration of thermal action to all studied diamonds, one may suggest different thermal regimes for different stones after their formation: from $1050^{\circ} \mathrm{C}$ to $1200^{\circ} \mathrm{C}$ for the conventional period of time at $3 \mathrm{Ga}$ (Taylor and Milledge, 1995).

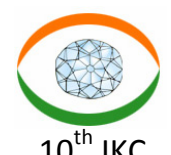




\section{$10^{\text {th }}$ International Kimberlite Conference-2012}

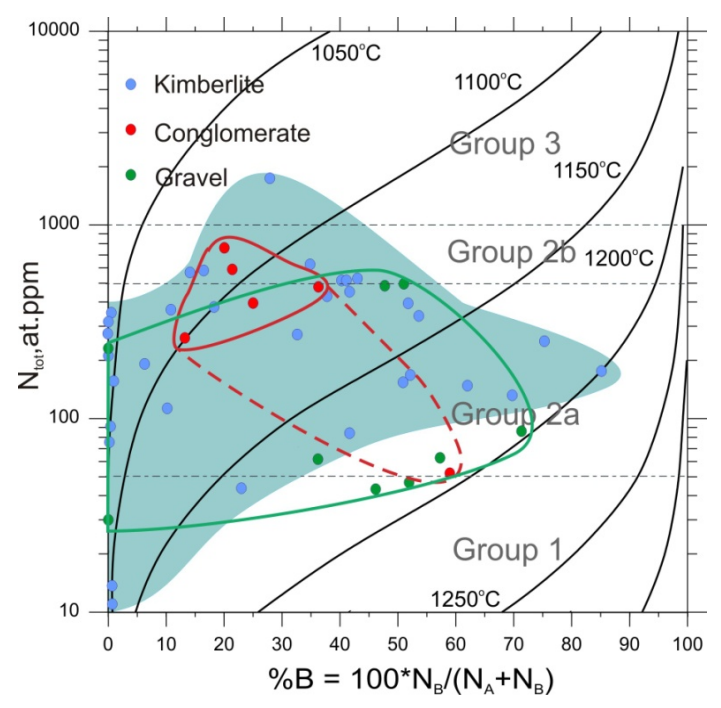

Fig.7. Nitrogen characteristics for diamonds from southern India. Isotherm curves for $3 \mathrm{Ga}$ after Taylor and Milledge (1995). Diamond groups after Kaminsky and Khachatryan (2001).

The 'platelet' (linear defects several atoms thick; Woods 1986) concentrations in arbitrary units $\left(\mathrm{cm}^{-1}\right)$ were calculated as a function of the absorption coefficient value measured at $1365 \mathrm{~cm}^{-1}$. Their values, like the nitrogen characteristics, vary in a wide range, from 0 to $21.4 \mathrm{~cm}^{-1}$ (Fig. 8). In this respect, they are similar to diamonds from other localities in the world, only the presence of low-platelets - low nitrogen-aggregated stones is unusual.

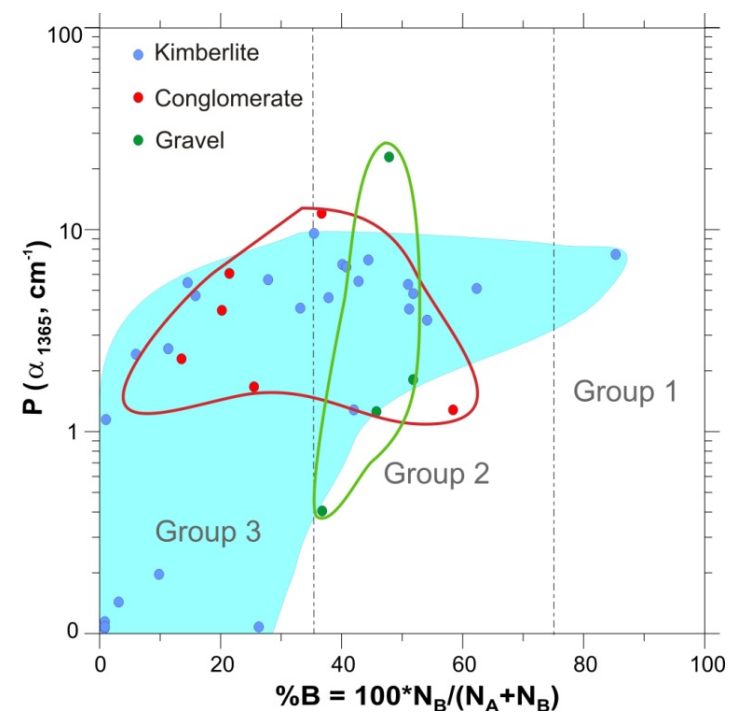

Fig.8. Distribution of 'platelets' (P) and aggregated nitrogen proportion $\left[\% \mathrm{~N}_{B}=100 * \mathrm{~N}_{\mathrm{B}} /\left(\mathrm{N}_{\mathrm{A}}+\mathrm{N}_{\mathrm{B}}\right)\right]$ in diamond from different regions (after Kaminsky and Khachatryan, 2001). P is an average 'platelet' content in diamond in arbitrary units as a function of the absorption coefficient value measured at $1365 \mathrm{~cm}^{-1}$.
The great variations both in nitrogen and platelet characteristics witness multiple mantle source regions for the studied diamonds. Among the kimberlitic stones, two groups of diamonds can be distinguished: (1) relatively low-nitrogen (pipes P1, P3, P6, P9, P10, CC1, CC2 and CC5), and (2) relatively high-nitrogen (pipes $\mathrm{P} 7, \mathrm{P} 8$ and TK4). Of particular interest and practical importance is the distribution of nitrogen characteristics in diamonds from kimberlites, ancient conglomerates and gravels. In both graphs (Figs. 7, 8) they form overlapping halos. This may be considered as an indication of the common source for all the three groups. This conclusion is only a suggestion based on a limited number of the stones analysed. A final conclusion can be made only on a basis of statistically representative number of analyses (50100 stones from each geological unit.

\section{REFERENCES}

Bokii, G.B., Bezrukov, G.N., Klyuev, Yu.A., Naletov, A.M., Nepsha, V.I. (1986) Natural and synthetic diamonds. Nauka Press, Moscow (in Russian).

Boyd, S. R., Kiflawi, I. and Woods, G. S. (1994) The relationship between infrared absorption and A-defect concentration in diamond. Phil. Mag., v.B69, pp. 1149-1153.

Boyd, S. R., Kiflawi, I. and Woods, G. S. (1995) Infrared absorption by the $\mathrm{B}$ nitrogen aggregate in diamond. Phil. Mag., v.B72, pp.351-361.

Kaminsky, F.V. and Khachatryan, G.K. (2001) Characteristics of nitrogen and other impurities in diamond, as revealed by infrared absorption data: Can. Mineralogist, v.39, pp.1733-1745.

Khachatryan, G.K. (2003) Improved methods of evaluating of nitrogen concentration in diamond and their practical application. Geological Material Base ALROSA, Mirny, pp.319-321(in Russian).

Khachatryan, G.K. (2010) Classification of diamonds from kimberlites and lamproites according to distribution of nitrogen centers in crystals. Rudi i Metalli (Ores and Metals), No.2, pp.46-60 (in Russian).

Mendelssohn, M.J. and Milledge, H.J. (1995) Geologically significant information from routine analysis of the mid-infrared spectra of diamonds. International Geol. Review, v.37, pp.95110 .

Mokievsky, V.A., Titova, V.M. and Bartoshinsky, Z.V. (1962) Manifestation of plastic deformation in diamond and some problems relating to the plasticity of crystals. Zap. Vses. Mineralog. Obshch., Part 91, No 4 (in Russian).

Taylor, W.R. and Milledge H.J. (1995) Nitrogen aggregation character, thermal history and stable isotope composition of some xenolith-derived diamonds from Roberts Victor and Finch. In: Sixth Internat. Kimberlite Conf. Extended Abstr., Novosibirsk, 1995, 620-622.

Wiens, R., Lal, D. and Craig, H. (1990) Helium and carbon isotopes in Indian diamonds. Geochim. Cosmochim. Acta, v.54, pp.25872591.

Woods, G.S. (1986) "Platelets" and the infrared absorption of type Ia diamonds. Proceedings of the Royal Society, London, A407, 219-238.

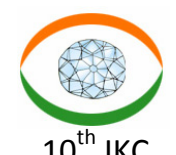

